University of Nebraska - Lincoln

DigitalCommons@University of Nebraska - Lincoln

$11-26-2002$

\title{
Molecular identification of natural hybrids between Trichinella nativa and Trichinella T6 provides evidence of gene flow and ongoing genetic divergence
}

\author{
G. La Rosa \\ Istituto Superiore di Sanita \\ G. Marucci \\ Istituto Superiore di Sanita \\ D.S. Zarlenga \\ U.S. Department of Agriculture, ARS, Immunology and Disease Resistance Laboratory
}

\author{
A. Casulli \\ Istituto Superiore di Sanita \\ R.L. Zarnke \\ Alaska Department of Fish and Game
}

See next page for additional authors

Follow this and additional works at: https://digitalcommons.unl.edu/usdaarsfacpub

Rosa, G. La; Marucci, G.; Zarlenga, D.S.; Casulli, A.; Zarnke, R.L.; and Pozio, E., "Molecular identification of natural hybrids between Trichinella nativa and Trichinella T6 provides evidence of gene flow and ongoing genetic divergence" (2002). Publications from USDA-ARS / UNL Faculty. 2242.

https://digitalcommons.unl.edu/usdaarsfacpub/2242

This Article is brought to you for free and open access by the U.S. Department of Agriculture: Agricultural Research Service, Lincoln, Nebraska at DigitalCommons@University of Nebraska - Lincoln. It has been accepted for inclusion in Publications from USDA-ARS / UNL Faculty by an authorized administrator of DigitalCommons@University of Nebraska - Lincoln. 


\section{Authors}

G. La Rosa, G. Marucci, D.S. Zarlenga, A. Casulli, R.L. Zarnke, and E. Pozio 


\title{
Molecular identification of natural hybrids between Trichinella nativa and Trichinella $\mathrm{T} 6$ provides evidence of gene flow and ongoing genetic divergence
}

\author{
G. La Rosa ${ }^{\mathrm{a}}$, G. Marucci ${ }^{\mathrm{a}}$, D.S. Zarlenga ${ }^{\mathrm{b}}$, A. Casulli ${ }^{\mathrm{a}}$, R.L. Zarnke ${ }^{\mathrm{c}}$, E. Pozio ${ }^{\mathrm{a}, *}$ \\ ${ }^{a}$ Laboratory of Parasitology, Istituto Superiore di Sanità, viale Regina Elena 299, 00161 Rome, Italy \\ ${ }^{\mathrm{b}}$ U.S. Department of Agriculture, ARS, Immunology and Disease Resistance Laboratory, Beltsville, MD 20705, USA \\ ${ }^{\mathrm{c}}$ Alaska Department of Fish and Game, 1300 College Road, Fairbanks, AK 99701, USA
}

Received 25 October 2002; received in revised form 26 November 2002; accepted 26 November 2002

\begin{abstract}
To date, there are no data available on the population genetics of Trichinella due to the lack of genetic markers and the difficulty of working with such small parasites. In the Arctic region of North America and along the Rocky Mountains, there exist two genotypes of Trichinella, Trichinella nativa and Trichinella T6, respectively, which are well differentiated by biochemical and molecular characters. However, both are resistant to freezing, show other common biological characters (e.g. low or no infectivity to rodents and swine) and produce fertile F1 offspring upon interbreeding. To data, these two genotypes have been considered allopatric. In this study, we detected both genotypes in wolves of the same wolf packs in Alaska, suggesting sympatry. A single GTT trinucleotide present in the ITS-2 sequence of $T$. nativa but not in Trichinella T6 was used as a genetic marker to study gene flow for this character in both a murine infection model and in larvae from naturally-infected Alaskan wolves. Only F1 larvae originating from a cross between T. nativa male and Trichinella T6 female were able to produce F2 offspring. Larvae (F1) originating from a cross between Trichinella T6 male and T. nativa female were not reproductively viable. As expected, all F1 larvae showed a heterozygote pattern for the GTT character upon heteroduplex analysis; however, within the F2 population, the number of observed heterozygotes $(n=52)$ was substantially higher than expected $(n=39.08)$, as supported by the $\mathrm{F}_{\text {is }}$ index, and was not in the Hardy-Weinberg equilibrium. Larvae from two of the 16 Trichinella positive Alaskan wolves, showed the Trichinella T6 pattern or the T. nativa/Trichinella T6 hybrid pattern. Our data demonstrate that T. nativa and Trichinella T6 live in sympatry at least in Alaskan wolves, where T. nativa occurs more frequently (69\%) than Trichinella T6 (31\%). One explanation for this phenomenon is that glacial periods may have caused a geographical relocation, colonisation and independent evolution of $T$. nativa within the Rocky Mountains, resulting in a bifurcation of the freeze-resistant genotype. Additional studies will be required to test this hypothesis. (C) 2002 Australian Society for Parasitology Inc. Published by Elsevier Science Ltd. All rights reserved.
\end{abstract}

Keywords: Trichinella nativa; Trichinella T6; Trichinella spiralis; Wolf; Heteroduplex; Hybrid; ITS-2; Microsatellite

\section{Introduction}

The existence of sibling species is very common in nematodes (Anderson et al., 1998). They have a conservative morphological architecture and, even when an accelerated rate of nucleotide substitution is observed both in mitochondrial (mt)-DNA (Okimoto et al., 1994; Hafner et al., 1994; Hoeh et al., 1996) and nuclear DNA (Thomas and Wilson, 1991; Fitch et al., 1995), their degree of morphological divergence seems to proceed slowly.

In Trichinella, biological, biochemical and molecular

\footnotetext{
* Corresponding author. Tel.: +39-06-4990-2304; fax: +39-06-49387065 .

E-mail address: pozio@iss.it (E. Pozio).
}

data have made it possible to provide a genus structure substantially more complex than originally proposed, consisting of least eight sibling species (Trichinella spiralis, Trichinella nativa, Trichinella britovi, Trichinella pseudospiralis, Trichinella murrelli, Trichinella nelsoni, Trichinella papuae and Trichinella zimbabwensis) (Murrell et al., 2000; La Rosa et al., 2001; Pozio et al., 2002). However, the taxonomic relationships of species remains undefined, and little is known about the population structure of the genus.

Within the genus, there exists a homogeneous collection of isolates, designated Trichinella T6 (Pozio et al., 1992), possessing a subset of molecular and biochemical characters unique enough to support a classification other than $T$. nativa, a species inhabiting arctic and subarctic areas of the Northern hemisphere in both Palearctic and Nearctic 
A

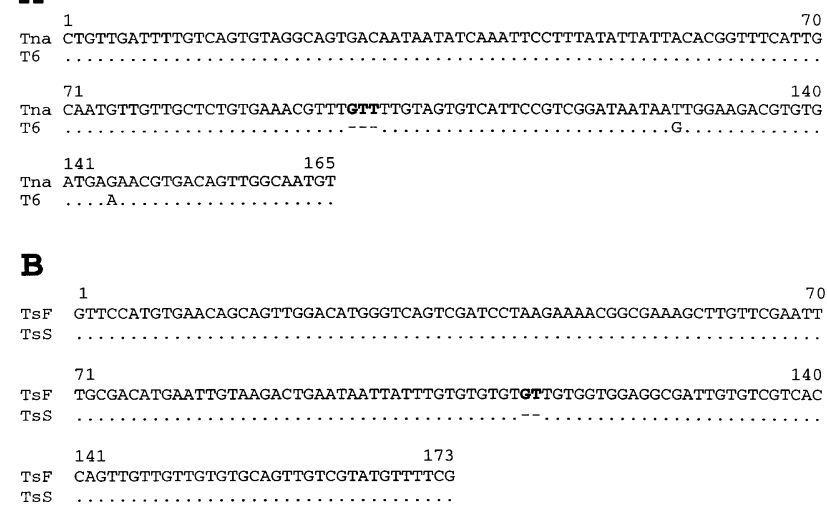

Fig. 1. Alignment of homologous ITS-2 sequences of Trichinella nativa (Tna) and Trichinella T6 (T6) isolates (A) and of homologous expansion segment five sequences of Trichinella spiralis isolates (B). (A) A single GTT trinucleotide (in bold and underlined) is present in T. nativa, but it is absent from Trichinella T6. (B) The isolate of Finland (TsF) shows the presence of five GT repeats, whereas the isolate of Sweden (TsS) shows the presence of four GT repeats. The fifth GT repeat of the Finnish isolate is in bold and underlined.

regions (Pozio, 2000). However, when all data available are considered collectively, they do not support unequivocally a species level classification for this genotype. Trichinella T6 has been found within carnivorous mammals along the Rocky Mountains in Idaho, Montana and Wyoming, although the northern and southern boundaries of distribution have yet to be defined (Pozio, 2000). There are two other reports of Trichinella T6 isolates in Pennsylvania and Ontario (Pozio, 2001); however, the geographical origins for both these isolates have not yet been determined.

Since their discovery, T. nativa and Trichinella T6 had not yet been found in sympatry (i.e. in the same geographical area and in the same host) (see Pozio, 2000), and viable F1 offspring have been produced only in breeding experiments (Britov, 1995). Consequently, Trichinella T6 has always been considered as a geographical variant of T. nativa. Recently, however, both T. nativa and Trichinella T6 were detected in the same packs of Alaskan wolves, suggesting that in nature, gene flow is possible between these two genotypes, which raises questions to their specific status.

Difficulties in studying the population genetics within the genus Trichinella, mainly due to the lack of polymorphic genetic markers and the inability to analyse single specimens, has limited our understanding of gene flow between T. nativa and Trichinella T6. Larvae of T. nativa and Trichinella T6 can be readily distinguished by multiplex PCR (Zarlenga et al., 1999) but, by virtue of its design, the multiplex PCR test is incapable of distinguishing heterozygote/hybrid patterns between these genotypes.

Herein, a heteroduplex assay was developed to distinguish between homozygotes and heterozygotes of $T$. nativa and Trichinella T6 in a murine model. This test was further shown to be applicable to investigate natural populations of Trichinella from several wolf packs in
Alaska. This assay was used to study the transmission of a GTT motif present within the second internal transcribed spacer (ITS-2) through multiple generations, in order to characterise the genetic structure of natural populations of T. nativa and Trichinella T6.

\section{Materials and methods}

\subsection{Trichinella isolates}

A T. nativa isolate (code ISS42) from Ursus maritimus from Alaska and a Trichinella T6 isolate (ISS34) from Ursus arctos horribilis from Montana were used to analyse the inheritance of an ITS-2 character to F1 and F2 generations. Comparing the ITS-2 sequence of several $T$. nativa and Trichinella T6 isolates (data not shown), a single GTT trinucleotide was discovered in T. nativa, which is absent from Trichinella T6. Sequence alignment of the ITS2 locus of T. nativa and Trichinella T6 identified two alleles, a 165 bp allele (homozygote status 165/165) in 10 larvae of T. nativa and a 162 bp allele (homozygote status 162/162) in 10 larvae of Trichinella T6 examined (Fig. 1A). This character was used as a genetic marker to distinguish between these two genotypes.

As a control in a conspecific system, genetic inheritance was analysed using two porcine isolates of $T$. spiralis, one from Finland (ISS297) and another from Sweden (ISS328). These two isolates were chosen because they have a fixed $(\mathrm{GT})_{n}$ microsatellite allele within expansion segment $\mathrm{V}$ (ESV). The ESV locus is present within the large subunit ribosomal DNA (lsrDNA), which is excised from the rRNA in Trichinella either before or coincident by the assembly of the ribosome (Zarlenga and Dame, 1992). Sequence alignment of the ESV locus of $T$. spiralis from Finland with that from Sweden showed the presence of two alleles of 173 and $171 \mathrm{bp}$, respectively. This sequence variation was observed between all 10 larvae of $T$. spiralis from Finland and the 10 others from Sweden (Fig. 1B). The Finnish isolate has a $(\mathrm{GT})_{5}$ microsatellite genotype defined herein as $173 / 173$, and the Swedish isolate a genotype of $171 / 171$, where the numerical designations define the length in bases of the PCR products.

To check the homozygote status of isolates ISS42, ISS34, ISS297, and ISS328, PCR products were cloned using pGEM-T System (Promega) according to the manufacturer's recommendations. At least three independent recombinant colonies were selected, and the cloned inserts were sequenced using a Perkin-Elmer ABI Prism 310 Genetic Analyser. The products of two independent amplification tubes were sequenced in both directions to confirm the nucleotide sequences.

During the 2000 and 2001 hunting seasons, tongues were collected from 57 wolves (Canis lupus) originating from an area in Alaska between $63-65^{\circ}$ North and $147-156^{\circ}$ West. Frozen muscle samples were sent by courier to the 
Table 1

Cross-breeding experiment of single male and female larvae of Trichinella nativa (Tna) vs. Trichinella T6 (T6) and of Trichinella spiralis of Finland (TsF) vs. T. spiralis of Sweden (TsS) in CD1 female mice

\begin{tabular}{|c|c|c|}
\hline Cross-breeding & $\begin{array}{l}\text { Infected/ } \\
\text { examined/ } \\
\text { inoculated mice }\end{array}$ & $\begin{array}{l}\text { Average larvae } \\
\text { per couple } \\
\text { (range) }\end{array}$ \\
\hline Tna $\sigma^{7} \times$ T6 $q$ & $8 / 8 / 10$ & $37(15-52)$ \\
\hline T6 ơ $\times$ Tna $q$ & $9 / 9 / 10$ & $30(8-41)$ \\
\hline Tna $\sigma^{\top} \times$ Tna $Q$ & $5 / 5 / 5$ & $76(43-97)$ \\
\hline $\mathrm{T} 60^{2} \times \mathrm{T} 69$ & $4 / 5 / 5$ & $54(19-68)$ \\
\hline $\begin{array}{l}\mathrm{F} 1 \sigma^{7}\left(\mathrm{Tna} \sigma^{7} \times \mathrm{T} 6 \text { o }\right) \times \mathrm{F} 1 q \\
\left(\mathrm{Tna} \sigma^{7} \times \mathrm{T} 6 \text { o }\right)\end{array}$ & $9 / 10 / 10$ & $9(5-18)$ \\
\hline 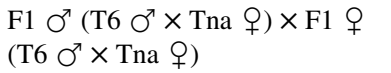 & $0 / 10 / 10$ & - \\
\hline TsF $\sigma^{2} \times \operatorname{TsS} \underset{+}{ }$ & $10 / 10 / 10$ & $198(87-238)$ \\
\hline $\mathrm{TsS} \sigma^{\top} \times \mathrm{TsF}$ ㅇ & $9 / 9 / 10$ & $231(115-287)$ \\
\hline $\mathrm{TsF} \mathrm{O}^{\prime} \times \mathrm{TsF} \stackrel{+}{+}$ & $4 / 4 / 5$ & $202(169-245)$ \\
\hline $\operatorname{TsS} \sigma^{7} \times \operatorname{TsS} q$ & $4 / 4 / 5$ & $226(154-257)$ \\
\hline 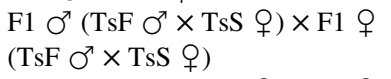 & $8 / 8 / 10$ & $213(147-251)$ \\
\hline $\begin{array}{l}\mathrm{F} 1 O^{7}\left(\mathrm{TsS} \sigma^{\top} \times \mathrm{TsF} q\right) \times \mathrm{F} 1 q \\
\left(\mathrm{TsS} \sigma^{7} \times \mathrm{TsF} q\right)\end{array}$ & $10 / 10 / 10$ & $209(113-274)$ \\
\hline
\end{tabular}

International Trichinella Reference Centre in Rome, Italy. Muscles were thawed and immediately digested with $1 \%$ pepsin and $0.5 \% \mathrm{HCl}$ at $37{ }^{\circ} \mathrm{C}$, according to standard procedures (Pozio, 1987).

\subsection{Cross-breeding}

To determine the transmission of genetic characters in cross-breeding experiments, it was imperative that the genotype of both the male and female be known. However, numerous obstacles were encountered in achieving this goal due to the enteral niche of Trichinella adults and their small size. Thus, for the experiments performed herein, the genotypes of the breeding male and female worms were inferred from concurrent analysis of other larvae collected from the same mouse (named as 'relatives' throughout the paper) and from validating that the relative larvae were homozygous for the designated genetic marker.

Larvae were collected after artificial digestion of skinned and eviscerated carcasses of infected mice, according to standard procedures (Pozio, 1987). Single male and female muscle larvae were identified under an inverted microscope on the basis of their morphological characters (Pozio et al., 1999). Two breeding experiments were set up: (1) T. nativa vs. Trichinella T6 in both senses (i.e. T. nativa male per Trichinella T6 female, and Trichinella T6 male per T. nativa female); and (2) T. spiralis of Finland vs. T. spiralis of Sweden in both senses (Table 1). For each mating, 10 mice ( $25 \mathrm{~g}, \mathrm{CD} 1$ female) were synchronically inoculated per os with single male and female larva to generate F1 larvae. Additionally, five mice were infected with a single male and female larva belonging to the same isolate as a control (Table 1). All mice were immunosuppressed with $4 \mathrm{mg}$ of cyclophosphamide at $-4,0$ and 4 days post infection (p.i.), to increase the number of larvae in the offspring. Mice were killed on day 35 p.i., and each skinned and eviscerated carcass was digested separately.

Individual F1 larvae were picked and suspended in $5 \mu \mathrm{l}$ of phosphate-buffered saline (PBS) for use in the genetic analysis of the ITS-2 (for T. nativa and Trichinella T6) or ESV (for T. spiralis) markers. The F2 generation was similarly produced by crossing single male and female F1 larvae in 10 mice. Mice harbouring the F2 larvae were killed on day 35 p.i. and processed as described above.

\subsection{Polymerase chain reaction}

For PCR amplification, DNA from single larvae was prepared as follows: Two microlitres of $5 \mathrm{mM}$ Tris $-\mathrm{HCl}$ ( $\mathrm{pH}$ 7.6) were added to the larva, overlaid with mineral oil, and heated at $90{ }^{\circ} \mathrm{C}$ for $10 \mathrm{~min}$. A total of $0.4 \mu \mathrm{l}$ of proteinase $\mathrm{K}(20 \mathrm{mg} / \mathrm{ml}$ stock $)$ and $2.6 \mu \mathrm{l}$ of $\mathrm{H}_{2} \mathrm{O}$ were then added to the mixture, and the solution was incubated at 48 ${ }^{\circ} \mathrm{C}$ for $3 \mathrm{~h}$ and later at $90{ }^{\circ} \mathrm{C}$ for $10 \mathrm{~min}$ to inactivate the proteinase K. PCR was performed in $50 \mu \mathrm{l}$ containing 0.5 unit ExTaq DNA polymerase (Takara Corp.), 1× ExTaq PCR buffer (Takara Corp.), $1.5 \mathrm{mM} \mathrm{MgCl}_{2}$ and $200 \mathrm{mM}$ dNTPs. To amplify the ITS-2 fragment, 50 pmol of the primer set ITS-2f $\left(5^{\prime}\right.$-CTG TTG ATT TTG TCA GTG TAG G-3') and ITS-2r (5'-ACA TTG CCA ACT GTC ACG-3') were used. Amplification was carried out for 35 cycles as follows: $94{ }^{\circ} \mathrm{C}$ for $30 \mathrm{~s}, 51{ }^{\circ} \mathrm{C}$ for $30 \mathrm{~s}$, and $72{ }^{\circ} \mathrm{C}$ for $60 \mathrm{~s}$. To amplify the ESV microsatellite, 50 pmol of the primer set oTsr1 (5'-CGA AAA CAT ACG ACA ACT GC-3') and oTsr4 (5'-GTT CCA TGT GAA CAG CAG T-3') were used (Zarlenga and Dame, 1992). Amplification was carried out for 35 cycles as follows: $94{ }^{\circ} \mathrm{C}$ for $30 \mathrm{~s}, 58^{\circ} \mathrm{C}$ for $30 \mathrm{~s}$, and $72{ }^{\circ} \mathrm{C}$ for $60 \mathrm{~s}$. Individual larvae collected from muscles of Alaskan wolves were identified by a multiplex PCR analysis, according to Zarlenga et al. (1999) and modified by Pozio and La Rosa (2002).

\subsection{Heteroduplex analysis}

The genotype of 'relative', F1 and F2 larvae was analysed by a heteroduplex assay (Delwart et al., 1993; Tang et al., 1995; Tang and Unnasch, 1997; White et al., 1992). PCR products of ITS-2 or ESV $(5 \mu 1)$ were mixed with an equal volume of formamide loading solution $(98 \%$ formamide, $10 \mathrm{mM}$ EDTA, $0.25 \%$ bromophenol blue, $0.25 \%$ xylene cyanole), heated for $5 \mathrm{~min}$ at $94{ }^{\circ} \mathrm{C}$, and immediately cooled in ice. Samples ( $3 \mu \mathrm{l})$ were loaded onto a $0.5-\mathrm{mm}$ thick, $6 \%$ denaturing polyacrylamide mini-gel $(10 \times 8 \mathrm{~cm})(29: 1$ acrylamide/bis; $5 \mathrm{M}$ urea) in $1 \times \mathrm{TBE}$ buffer ( $88 \mathrm{mM}$ Tris, $89 \mathrm{mM}$ boric acid, $2 \mathrm{mM}$ EDTA), and subjected to electrophoresis at $100 \mathrm{~V}$ for $35 \mathrm{~min}$.

Heteroduplex analysis was carried using solutions of either $100 \%$ complementary DNA strands $(+/+$ or $-/-)$, which produces a homoduplex and therefore a single 

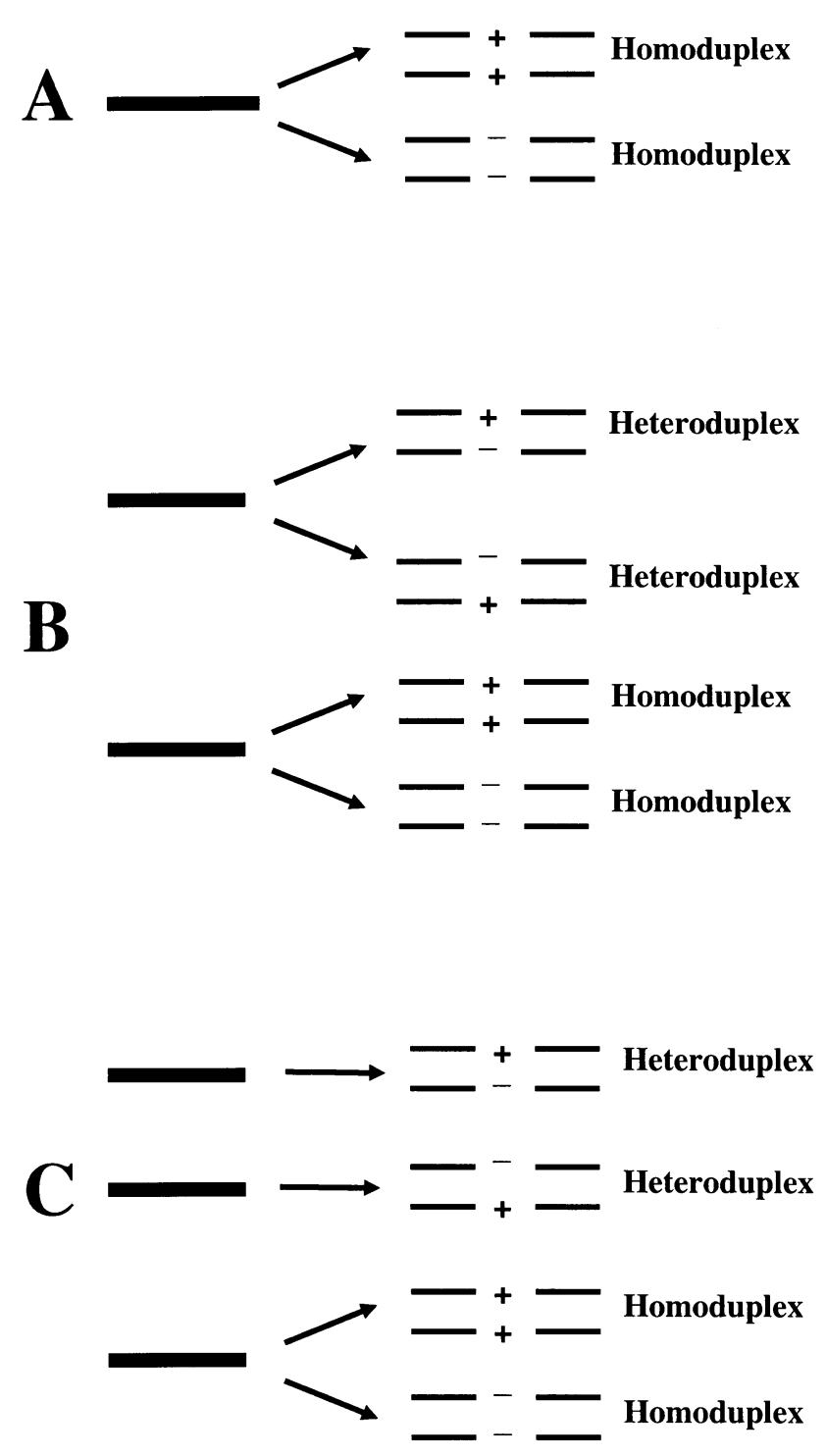

Fig. 2. Schematic representation of heteroduplex analysis products from single larvae. (A) Single band pattern detected in larvae with the following genotypes: 173/173 (Trichinella spiralis of Finland) and 171/171 ( $T$. spiralis of Sweden); 165/165 (Trichinella nativa) and 162/162 (Trichinella T6). (B) Double-banded pattern detected in larvae with the following genotypes: $173 / 171$ and 171/173. (C) Triple band pattern detected in larvae with the following genotypes: $165 / 162$ and $162 / 165$. The symbols ' + ' and ' - ' show the presence or the absence of the GTT trinucleotide or of a GT repeat in double stranded molecules.

migrating band on gel electrophoresis, or from two strands, which are not $100 \%$ complementary $(+/-$ and $-/+)$, which in turn produce a heteroduplex and thus represent multiple electrophoretic bands due to structural constraints imposed on the duplex by partial complementarity (Tang and Unnasch, 1997) (see Fig. 2).

To resolve the identity of unknown homozygotes into molecules $+/+$ or $-/-, 5 \mu l$ of the PCR product from the larvae showing a single band were mixed in duplicate with 5 $\mu l$ of the PCR reaction obtained from 'relatives' of parents with a known genotype, and the heteroduplex analysis was performed again. Samples showing a single electrophoretic band revealed unequivocally the identity of their homozygous status.

The re-associating double-stranded molecules were coded as follows: (1) homoduplexes ITS-2 ${ }^{165 / 165}$ and ITS$2^{162 / 162}$ and heteroduplexes ITS-2 $2^{165 / 162}$ and ITS- $2^{162 / 165}$, refer to T. nativa and Trichinella T6; and (2) homoduplexes $\mathrm{ESV}^{173 / 173}$ and $\mathrm{ESV}^{171 / 171}$ and heterduplexes ESV ${ }^{173 / 171}$ and $\mathrm{ESV}^{171 / 173}$, refer to T. spiralis isolates from Finland or Sweden. We refer to the inferred diploid genotypes using the codes $165 / 165$ or $162 / 162$, and $173 / 173$ or $171 / 171$.

\subsection{Statistical analysis}

GENEPOP 3.3 (Raymond and Rousset, 1995) was used to compute the following values: (1) allelic frequencies; (2) observed and expected heterozygotes; (3) the $\mathrm{F}_{\text {is }}$ index used to measure the departure of F2 from the Hardy-Weinberg equilibrium (Weir and Cockerham, 1984); and (4) the $P$ value, the probability of accepting that the null hypothesis (i.e. the Hardy-Weinberg expectation) was fulfilled.

\section{Results}

Heteroduplex analysis of 30 single larvae of both males and females from each breeding strain, revealed a single larval product for ITS-2 $(\sim 160 \mathrm{bp})$ for $T$. nativa and Trichinella T6, or for ESV ( $\sim 170 \mathrm{bp})$ for T. spiralis in the absence of heteroduplexes. These results confirmed the effectiveness of the assay and the absence of heterozygotes in the larvae considered 'relatives' of those used for crossbreeding experiments.

\subsection{Trichinella nativa vs. Trichinella T6 in a laboratory model}

Breeding experiments between T. nativa and Trichinella T6 produced F1 viable offspring in both senses (Table 1). Heteroduplex analysis of the ITS-2 locus of 200 F1 larvae showed that all larvae were heterozygotes based on the presence of three bands (Fig. 3A and Table 2) where the band at the bottom refers to the co-migrating homoduplexes ITS-2 $2^{165 / 165}$ and ITS-2 $2^{162 / 162}$, and the upper bands to the heteroduplex products ITS-2 ${ }^{165 / 162}$ and ITS-2 $2^{162 / 165}$. The heterozygote genotype, 165/162, was observed in all F1 larvae.

Only F1 larvae originating from the cross between $T$. nativa male and Trichinella T6 female were able to produce F2 offspring, whereas F1 larvae originating from the cross between Trichinella $\mathrm{T} 6$ male and T. nativa female were not. Heteroduplex analysis of 83 F2 larvae showed the presence of samples with one or three bands (Fig. 3A) where the single-banded pattern was due to the presence of ITS- $2^{165 /}$ 165 or ITS-2 ${ }^{162 / 162}$ homoduplexes (Fig. 3B). In the threeband pattern, the lower band was the same as that of the single band pattern (see above), whereas the upper bands 


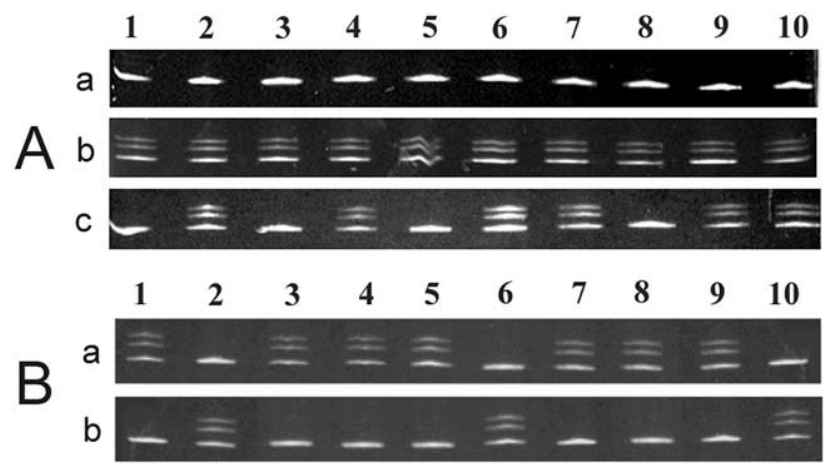

Fig. 3. Heteroduplex analysis of the ITS-2 locus of larvae, which are 'relatives' of parents of F1 larvae and of F1 and F2 larvae obtained crossing Trichinella nativa and Trichinella T6. (A) a: Heteroduplex products obtained from single 'relative' larvae. Lines 1-5, Trichinella nativa isolate (165/165); lines 6-10, Trichinella T6 isolate (162/162); b: Products of F1 single larvae. 165/165 and 162/162 (lower band), 165/162 and 162/165 (intermediate and upper bands). c: Products of F2 single larvae. Lines 1, 3, 5 and $8,162 / 162$ or $165 / 165$; lines $2,4,6,7,9$ and $10,165 / 165$ and $162 / 162$ (lower band), 165/162 and 162/165 (intermediate and upper bands). (B) Resolution of the genotype of F2 homozygote larvae from T. nativa and Trichinella T6 by heteroduplex analysis. a,b: Lines $1,3-5$ and 7-9, homozygote larvae of Trichinella T6; lines 2, 6 and 10, homozygote larvae of $T$. nativa. Heteroduplex patterns were obtained mixing $5 \mu l$ of the PCR reaction of F2 larvae with $5 \mu 1$ of the PCR reaction obtained from $T$. nativa (a) and from Trichinella T6 (b) 'relative' larvae.

were due to ITS-2 $2^{165 / 162}$ and ITS-2 $2^{162 / 165}$ re-associating molecules implicating the heterozygous genotype (Fig. 3B).

In the F1 larvae, the numbers of observed and expected heterozygotes was equal (Table 2). However, in the F2 larvae, the number of observed heterozygotes $(n=52$, $62.6 \%$ was substantially different from the number expected $(n=39.08)$. This was supported by an $F_{\text {is }}$ index value of $-0.333(P>0.1)$, which showed that the examined F2 population had an excess of heterozygotes and was thus not in Hardy-Weinberg equilibrium (Table 2).

\subsection{Trichinella spiralis vs. T. spiralis in a laboratory model}

Cross-breeding experiments between $T$. spiralis from Finland and T. spiralis from Sweden produced F1 viable offspring in both senses (Table 1). In the F1 larvae, the number of observed heterozygotes was approximately equal to the number expected (Fig. 4A and Table 2). In the F2 larvae, the number of observed heterozygotes $(n=50)$ was also as expected $(n=49.93)$. These numbers were supported by the $\mathrm{F}_{\text {is }}$ index value of $+0.001(P<0.001)$, which shows that the F2 population examined was in HardyWeinberg equilibrium (Fig. 4A, B and Table 2).

\subsection{Trichinella from Alaskan wolves}

Of 57 wolves examined, $16(28 \%)$ were positive for Trichinella with an average infection rate of 2.9 larvae/g (range 0.06-12.0 larvae/g). Larvae showing the multiplex PCR pattern characteristic of T. nativa were detected in 11 wolves (19\% of examined wolves, 69\% of 'positive' wolves). The multiplex PCR pattern characteristic of Trichinella $\mathrm{T} 6$ or of a T. nativa/Trichinella T6 hybrid was detected for larvae from five wolves (9\% of examined wolves, $31 \%$ of 'positive' wolves) (Fig. 5). However, when larvae exhibiting the Trichinella T6 pattern were examined by heteroduplex analysis, those from two wolves (code nos. 4210 and $4212 ; 12.5 \%$ of 'positive' wolves) showed either the Trichinella T6 pattern (75 and $40 \%$ of larvae,

Table 2

Allelic frequencies and expected and observed heterozygosis of 'relatives' of F1 parents and of F1 and F2 larvae of: (1) Trichinella nativa (Tna) and Trichinella T6 (T6), (2) two porcine isolates of Trichinella spiralis (of Finland, TsF and of Sweden, TsS), which show an alternative homozygous status 171/171 (TsS) or 173/173 (TsF) at the ESV locus for the GT microsatellite; observed homozygote (only T6 pattern) and heterozygote larvae (Tna and T6) detected in two wolves from Alaska

\begin{tabular}{|c|c|c|c|c|c|c|c|c|c|c|c|}
\hline \multirow{2}{*}{$\begin{array}{l}\text { Examined generations } \\
\text { (isolate code) }\end{array}$} & \multirow[t]{2}{*}{ No. of examined larvae } & \multicolumn{3}{|c|}{ GTT genotype } & \multicolumn{3}{|c|}{ GT genotype } & \multirow[t]{2}{*}{$\mathrm{He}^{\mathrm{a}}$} & \multirow[t]{2}{*}{$\mathrm{Ho}^{\mathrm{b}}$} & \multirow[t]{2}{*}{$F_{\text {is }}$ index ${ }^{c}$} & \multirow[t]{2}{*}{$P$} \\
\hline & & $165 / 165$ & $\begin{array}{l}165 / 162 \\
162 / 165\end{array}$ & $162 / 162$ & $173 / 173$ & $\begin{array}{l}173 / 171 \\
171 / 173\end{array}$ & $171 / 171$ & & & & \\
\hline
\end{tabular}

\begin{tabular}{|c|c|c|c|c|c|c|c|c|c|c|c|}
\hline Tna 'relatives' $\mathrm{d}$ & 30 & 30 & 0 & 0 & - & - & - & - & - & - & - \\
\hline $\mathrm{T} 6$ 'relatives ${ }^{\mathrm{d}}$ & 30 & 0 & 0 & 30 & - & - & - & - & - & - & - \\
\hline $\mathrm{F} 1($ Tna $\times \mathrm{T} 6)$ & 200 & 0 & 200 & 0 & - & - & - & 200 & 200 & - & - \\
\hline $\mathrm{F} 2(\mathrm{~F} 1 \times \mathrm{F} 1)^{\mathrm{e}}$ & 83 & 5 & 52 & 26 & - & - & - & 39.08 & 52 & -0.333 & $>0.1$ \\
\hline TsF 'relatives' $\mathrm{d}$ & 30 & - & - & - & 30 & 0 & 0 & - & - & - & - \\
\hline TsS 'relatives' ${ }^{\mathrm{d}}$ & 30 & - & - & - & 0 & 0 & 30 & - & - & - & - \\
\hline $\mathrm{F} 1(\mathrm{TsS} \times \mathrm{TsF})$ & 100 & - & - & - & 0 & 100 & 0 & 100 & 100 & - & - \\
\hline $\mathrm{F} 2(\mathrm{~F} 1 \times \mathrm{F} 1)^{\mathrm{f}}$ & 100 & - & - & - & 22 & 50 & 28 & 49.93 & 50 & +0.001 & $<0.001$ \\
\hline Larvae of wolf No. 4210 & 10 & 0 & 6 & 4 & - & - & - & - & - & - & - \\
\hline Larvae of wolf No. 4212 & 8 & 0 & 2 & 6 & - & - & - & - & - & - & - \\
\hline
\end{tabular}

\footnotetext{
${ }^{\text {a }}$ Expected heterozygotes.

${ }^{\mathrm{b}}$ Observed heterozygotes.

c Calculated according to Weir and Cockerham (1984).

${ }^{d}$ Larvae of the same generation of F1 parents.

e $\mathrm{F} 2$ offspring from $\mathrm{F} 1$ of Tna $\times \mathrm{T} 6$.

${ }^{\mathrm{f}} \mathrm{F} 2$ offspring from $\mathrm{F} 1$ of $\mathrm{TsF} \times \mathrm{TsS}$.
} 


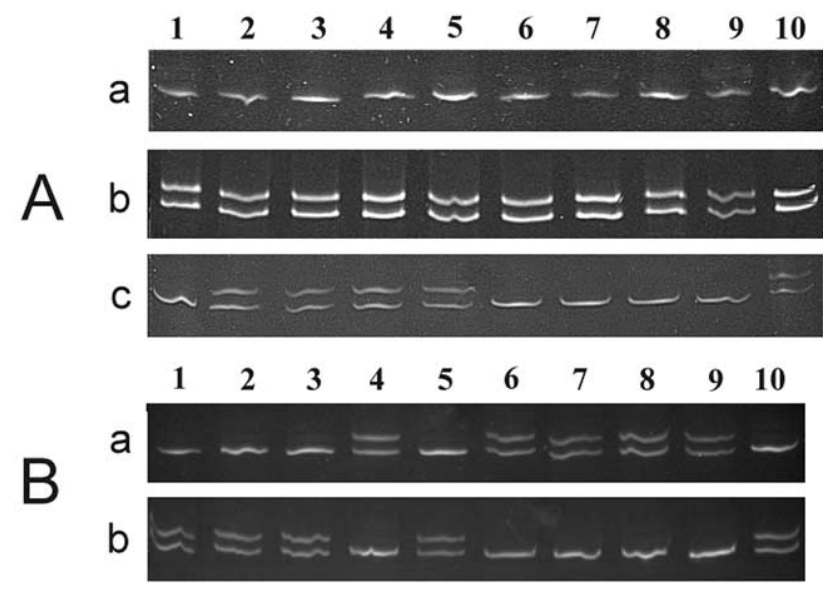

Fig. 4. Heteroduplex analysis of the expansion segment five of larvae, which are 'relatives' of parents of F1 larvae and of F1 and F2 larvae obtained crossing Trichinella spiralis of Finland (TsF) with T. spiralis of Sweden (TsS). (A) a: Heteroduplex products obtained from single larvae, which are 'relative' of parents of F1 larvae. Lines 1-5, Finnish isolate (173/173); lines 6-10, Swedish isolate (171/171). b: Products of F1 single larvae: 173/173 and 171/171 (lower band), and 173/171 and 171/173 (upper band). c: Products of F2 single larvae. Lines $1-10,173 / 173$ or 171/171 (lower band) and lines 2-5 and 10, 173/171 or 171/173 (upper band). (B) Resolution of the genotype of homozygote F2 larvae. a,b: Lines 1-3, 5, and 10, 173/173 homozygote larvae of TsF; lines 4, 6-9, 171/171 homozygote larvae of TsS. Heteroduplex patterns were obtained mixing $5 \mu$ lof the PCR reaction of F2 larvae with $5 \mu 1$ of the PCR reaction obtained from TsF (a) and from TsS (b) 'relative' larvae.

respectively) or the $T$. nativa/Trichinella T6 hybrid pattern (25 and 60\% of larvae, respectively) (Fig. 6 and Table 2).

\section{Discussion}

The ability to resolve allelic variation in the ITS- 2 alleles in T. nativa and Trichinella T6 isolates, which are biochemically and genetically distinct, but able to interbreed, gave us the opportunity to study the transmission of this molecular character through multiple generations. Furthermore, the detection of an ESV polymorphism in $T$. spiralis offered us the chance to study and compare the transmission of a genetic character in a fully conspecific system, and to use this system as a control for the heteroduplex assay developed.

In the past, the existence of gene flow between isolates of the same Trichinella species was postulated on the basis of

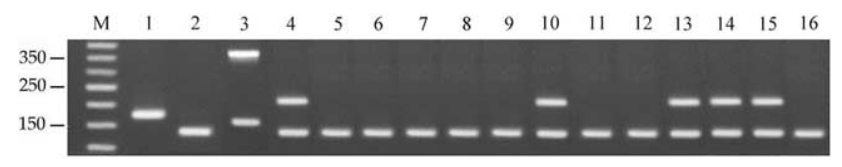

Fig. 5. Electrophoretic pattern after multiplex polymerase chain reaction amplification of Trichinella larvae of Alaskan wolves (lanes 5-16). Lane 1, Trichinella spiralis reference larva (code ISS3); lane 2, Trichinella nativa reference larva (code ISS42); lane 3, Trichinella murrelli reference larva (code ISS35); lane 4, Trichinella T6 reference larva (code ISS34); lanes 59, 11, 12 and 16, T. nativa; lanes 10 and 13-15, Trichinella T6. Lanes M, 100 bp ladder (Amersham-Pharmacia Biotech).

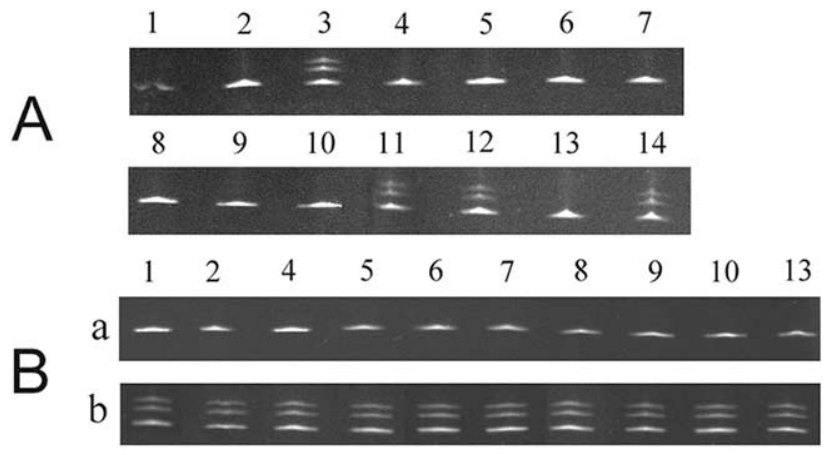

Fig. 6. Heteroduplex analysis of the ITS-2 locus of larvae from Alaskan wolves. (A) Lines 1, 2, 4-10 and 13, homozygote larvae 162/162 (Trichinella T6, T6); lines 3, 11, 12 and 14, heterozygote larvae 165/162 and 162/165 (Trichinella nativa/T6 hybrid larvae). (B) Resolution of the genotype of homozygote larvae. a,b: Lines 1, 2, 4-10 and 13, 162/162 homozygote larvae of Trichinella T6. Heteroduplex patterns were obtained mixing $5 \mu \mathrm{l}$ of the PCR reaction of larvae with $5 \mu \mathrm{l}$ of the PCR reaction obtained from Trichinella T6 (a) and from T. nativa (b) 'relative' larvae.

the high number of mixed natural infections with two different species detected in the same host (Pozio et al., 1995, 1997; Pozio, 2000). Unfortunately, these experiments were conducted without the availability of genetic markers or laboratory techniques which would permit us to study population dynamics within the genus Trichinella. The first attempt to use molecular characters to study hybridisation within F1 offspring obtained by cross-breeding a pool of larvae belonging to two different species, i.e. Trichinella spiralis and Trichinella britovi, was that of Wu et al. (2000), who showed a heterogeneous transmission pattern based upon five characters not including ITS-2 and ESV. In the present study, two different characters, the ITS-2 and ESV, were used. Both markers were derived from nuclear ribosomal DNA and are regarded as neutral characters (Gasser and Newton, 2000). It is unclear whether the results of ITS-2 and ESV are directly comparable between them. In addition, because both characters lie within the ribosomal gene array and $\sim 1500-1700$ bases apart, it has been proposed that they belong to the same recombination unit or linkage group and, thus, are predicted to be inherited in a similar fashion during any hybridisation event. Consequently, it is suggested that both characters share a similar evolution.

The results of breeding experiments showed a different behaviour in T. nativa vs. Trichinella T6 when compared with conspecific isolates (i.e. $T$. nativa vs. $T$. nativa, Trichinella T6 vs. Trichinella T6, and T. spiralis vs. T. spiralis). Trichinella nativa and Trichinella T6 were able to interbreed in both direction producing a fertile F1 offspring even if the reproductive capacity of $T$. nativa vs. Trichinella T6 (in both directions) and that of their F1 offspring were lower than that of the parents (Table 1). Furthermore, the $F_{\text {is }}$ values of F2 offspring originating from $T$. nativa vs. Trichinella T6 and from $T$. spiralis from Finland vs. $T$. spiralis from Sweden showed opposite results with respect to Hardy-Weinberg expectations, where T. nativa/Trichi- 
nella T6 hybrids exhibited an imbalance of heterozygotes under both experimental and natural conditions. The $T$. spiralis model demonstrated clearly that the homozygote/ heterozygote balance was in agreement with HardyWeinberg expectations. These results are consistent with some level of biological separation between $T$. nativa and Trichinella T6.

Both markers analysed, GTT (ITS-2) and GT (ESV), are located within ribosomal genes. In eukaryote ribosomal genes are usually structured as multiple arrays that are repeated in tandem up to thousands of times. According to the theory of concerted evolution, there is a strong tendency for these repeats to be identical in sequence due to the process of homogenisation both in individuals and in populations (Arnheim, 1983). However, in nematodes, concerted evolution sometimes fails to homogenise the arrays and, hence, more than one type of repeat can be generated within a single worm (Back et al., 1984; Burke et al., 1995; Zarlenga et al., 1994). If this process occurs within Trichinella, the present results could be due to variability between worms and not between populations. However, the data presented herein are inconsistent with intra-worm sequence variation in the ITS-2 in that heteroduplex products in parental worms was not detected. On the contrary, only the heterozygotes showed heteroduplex products as result of a mixture of two alternative parental alleles.

It is possible that the 'germ-line', characterised by the presence of hologonic gonads (Murrell et al., 2000), could influence the allele frequencies of the putative neutral ITS-2 character from one generation to the next, if cell lines harbouring different genotypes 'grow' at different rates. To control for this possibility, the same procedures used to study hybridisation between T. nativa and Trichinella T6 were used to study hybridisation between isolates of the same species of $T$. spiralis fixed at alternative alleles for the ESV locus. However, currently, there is no evidence available indicating that multiple loci for sperm or egg production influence the genetic make-up of the progeny.

Genetic analysis of Trichinella larvae from Alaskan wolves allowed us to investigate the relationship between $T$. nativa and Trichinella T6. The biology of both genotypes is influenced by low environmental temperatures, i.e. T. nativa in arctic regions and Trichinella T6 in the Rocky Mountains, where larvae of both genotypes can survive freezing for years in muscles of carnivores (Pozio, 2000). It can be speculated that separation of these genotypes may have occurred during glacial periods, when ice overspread the southern regions of North America and T. nativa isolates living in the arctic colonised the Rocky Mountains. When the glacial period ended, the ice withdrew and left behind the arctic-derived, freeze resistant Trichinella isolates, which remained restricted to the Rocky Mountains as a glacial relict. This would have resulted in restricted gene flow with arctic isolates, and Trichinella T6 could have begun an evolutionary path independent from $T$. nativa.
Today, differentiation between them is supported by distinct biochemical and molecular characters. Due to their evolution in allopatry, T. nativa and Trichinella T6 would have diverged as a result of their geographical separation where mating barriers were not involved (see Kunz, 2002). Anectodal support for this supposition lies in sequence data obtained from the entire small subunit ribosomal DNA of both genotypes which showed no differences, whereas a low degree of variation was shown between these genotypes and other species of Trichinella (D.S. Zarlenga, unpublished data).

In conclusion, T. nativa and Trichinella $\mathrm{T} 6$ have been detected in sympatry in Alaskan wolves, where T. nativa appears to be more frequent $(69 \%)$ than Trichinella $\mathrm{T} 6$ $(31 \%)$. Analysis of the genetic structure of the ITS-2 locus has shown that gene flow occurs between $T$. nativa and Trichinella T6 in nature. In laboratory conditions, however, the results show an imbalance in the Hardy-Weinberg expectations, suggesting that the two genotypes do not have the same weight in the transmission of their respective genetic arrays. It can be speculated that, under selection due to the sympatry, the present condition can evolve in two different ways, either a complete divergence into two distinct species, or a re-homogenisation of the two genotypes. In addition, the heteroduplex assay developed herein was able to discriminate small differences between gene fragments and can be considered a useful tool for further studies on the population genetics of Trichinella.

\section{Acknowledgements}

We are grateful to F. Mancini Barbieri and Marco Amati for their technical support. This work received financial support from the project 'Strategie per un' accurata e rapida risposta ai pericoli microbici emergenti veicolati da alimenti' of the Italian Ministry of Health, Contract 9D/F, and from the project 'TRICHIPORSE' of the European Union, Contract QLK1-CT-2001-01156.

\section{References}

Anderson, T.J., Blouin, M.S., Beech, R.N., 1998. Population biology of parasitic nematodes: applications of genetic markers. Adv. Parasitol. 41, 219-283.

Arnheim, N., 1983. Concerted evolution of multigene families. In: Nei, M., Koehn, R.K. (Eds.), Evolution of Genes and Proteins, Sinauer, Sunderland MA, pp. 38-61.

Back, E., Felder, H., Muller, F., Tobler, H., 1984. Chromosomal arrangement of the two main rDNA size classes of Ascaris lumbricoides. Nucleic Acids Res. 12, 1333-1347.

Britov, V.A., 1995. Trichinellosis problem in the Primorsk region, Veterinary Scientific Research Institute of the Far East, Primorsk branch, Vladivostok, pp. 1-51 in Russian.

Burke, W.D., Müller, F., Eickbush, T.H., 1995. R4, a non R4-LTR retrotransposon specific to the large subunit rRNA gene of nematodes. Nucleic Acids Res. 23, 4628-4634. 
Delwart, E.L., Shpaer, E.G., Louwagie, J., McCutchan, F.E., Grez, M., Rübsamen-Waigmann, H., Mulins, J.I., 1993. Genetic relationships determined by a DNA heteroduplex mobility assay: analysis of HIV-1 env genes. Science 262, 1257-1261.

Fitch, D.H.A., Bugaj-Gaweda, B., Emmons, S.W., 1995. 18S ribosomal RNA gene phylogeny for some Rhabditidae related to Caenorhabditis. Mol. Biol. Evol. 12, 346-358.

Gasser, R.B., Newton, S.E., 2000. Genomic and genetic research on bursate nematodes: significance, implications and prospects. Int. J. Parasitol. 30, 509-534.

Hafner, M.S., Sudman, P.D., Villablanca, F.X., Spradling, T.A., Demastes, J.W., Nadler, S.A., 1994. Disparate rates of molecular evolution in cospeciating hosts and parasites. Science 265, 1087-1090.

Hoeh, W.R., Stewart, D.T., Sutherland, B.W., Zouros, E., 1996. Cytochrome c oxidase sequence comparisons suggest an unusually high rate of mitochondrial DNA evolution in Mytilus (Mollusca: Bivalvia). Mol. Biol. Evol. 13, 418-421.

Kunz, W., 2002. When is a parasite a species? Trends Parasitol. 18, $121-124$

La Rosa, G., Marucci, G., Zarlenga, D.S., Pozio, E., 2001. Trichinella pseudospiralis populations of the Palearctic region and their relationship with populations of the Nearctic and Australian regions. Int. J. Parasitol. 31, 297-305.

Murrell, K.D., Lichtenfels, R.J., Zarlenga, D.S., Pozio, E., 2000. The systematics of Trichinella with a key to species. Vet. Parasitol. 93, 293-307.

Okimoto, R., Macfarlane, J.L., Wolstenholme, D.R., 1994. The mitochondrial ribosomal RNA genes of the nematodes Caenorhabditis elegans and Ascaris suum: consensus secondary-structure models and conserved nucleotide sets for phylogenetic analysis. J. Mol. Evol. 39, $598-613$.

Pozio, E., 1987. Isoenzymatic typing of 23 Trichinella isolates. Trop. Med. Parasitol. 38, 111-116.

Pozio, E., 2000. The domestic, synanthropic and sylvatic cycles of Trichinella and the flow among them. Vet. Parasitol. 93, 241-262.

Pozio, E., 2001. New patterns of Trichinella infections. Vet. Parasitol. 98, $133-148$.

Pozio, E., La Rosa, G., 2002. PCR-derived methods for the identification of Trichinella parasites from animal and human samples. In: Sachse, K., Frey, J. (Eds.), PCR Detection of Microbial Pathogens: Methods and Protocols, Methods in Molecular Biology, Humana Press, Totowa, NJ, pp. 299-309.

Pozio, E., La Rosa, G., Murrell, K.D., Lichtenfels, J.R., 1992. Taxonomic revision of the genus Trichinella. J. Parasitol. 78, 654-659.

Pozio, E., Bandi, C., La Rosa, G., Järvis, T., Miller, I., Kapel, C.M., 1995. Concurrent infection with sibling Trichinella species in a natural host. Int. J. Parasitol. 25, 1247-1250.
Pozio, E., Serrano, F.J., La Rosa, G., Reina, D., Perez-Martin, E., Navarrete, I., 1997. Evidence of potential gene flow in Trichinella spiralis and in Trichinella britovi in Nature. J. Parasitol. 83, 163-166.

Pozio, E., Owen, I.L., La Rosa, G., Sacchi, L., Rossi, P., Corona, S., 1999. Trichinella papuae n.sp. (Nematoda), a new non-encapsulated species from domestic and sylvatic swine of Papua New Guinea. Int. J. Parasitol. 29, 1825-1839.

Pozio, E., Foggin, C.M., Marucci, G., La Rosa, G., Sacchi, L., Corona, S., Rossi, P., Mukaratirwa, S., 2002. Trichinella zimbabwensis n.sp. (Nematoda), a new non-encapsulated species from crocodiles (Crocodylus niloticus) in Zimbabwe also infecting mammals. Int. J. Parasitol. 32, 1787-1799.

Raymond, M., Rousset, F., 1995. GENEPOP (version 1.2): population genetics software for exact tests and ecumenicism. J. Hered. 86, 248-249.

Tang, J., Unnasch, T.R., 1997. Heteroduplex analysis in medical entomology: a rapid and sensitive sequence-based tool for population and phylogenetic studies. Parasitol. Today 13, 271-274.

Tang, J., Toè, L., Back, C., Zimmerman, P.A., Pruess, K., Unnasch, T.R., 1995. The Simulium damnosum species complex: phylogenetic analysis and molecular identification based upon mitochondrial encoded gene sequences. Insect Mol. Biol. 4, 79-88.

Thomas, W.K., Wilson, A.C., 1991. Mode and tempo of molecular evolution in the Nematode Caenorhabditis: Cytochrome oxidase II and calmodulin sequences. Genetics 128, 269-279.

Weir, B.S., Cockerham, C.C., 1984. Estimating F-statistics for the analysis of population structure. Evolution 38, 1358-1370.

White, M.B., Carvalho, M., Derse, D., O’Brien, S.J., Dean, M., 1992. Detecting single base substitutions as heteroduplex polymorphisms. Genomics 12, 301-306.

Wu, Z., Nagano, I., Matsuo, A., Takahashi, Y., 2000. The genetic analysis of F1 hybrid larvae between female Trichinella spiralis and male Trichinella britovi. Parasitol. Int. 48, 289-295.

Zarlenga, D.S., Dame, J.B., 1992. The identification and characterization of a break within the large subunit ribosomal RNA of Trichinella spiralis: comparison of gap sequences within the genus. Mol. Biochem. Parasitol. 51, 281-289.

Zarlenga, D.S., Stringfellow, F., Nobary, M., Lichtenfels, J.R., 1994. Cloning and characterization of ribosomal RNA genes from three species of Haemonchus (Nematoda: Trichostrongyloidea) and identification of PCR primers for rapid differentiation. Exp. Parasitol. 78, 28-36.

Zarlenga, D.S., Chute, M.B., Martin, A., Kapel, C.M., 1999. A multiplex PCR for unequivocal differentiation of all encapsulated and nonencapsulated genotypes of Trichinella. Int. J. Parasitol. 29, 1859-1867. 